\title{
Faster Inversion Recovery Prepared T1 weighted segmented turbo field echo sequence (IR-TFE): Evaluating options for eliminating the start-up shot
}

\author{
Ramkumar Krishnamurthy ${ }^{1 *}$, Amol Pednekar ${ }^{2}$, Benjamin Cheong $^{3}$, Raja Muthupillai ${ }^{3}$ \\ From 2011 SCMR/Euro CMR Joint Scientific Sessions \\ Nice, France. 3-6 February 2011
}

\section{Introduction}

In conventional multi-shot IR-TFE sequences, e.g., clinical myocardial viability imaging, data collected during the first one or two shots is ignored, to minimize signal intensity variation across the shots. For a typical 8-10 heartbeat acquisition, such dummy shots results in scan overhead of $10-15 \%$ longer scan time. We evaluate the effect of removing the start-up shots in such IR-TFE sequences, and minimizing the effect of resulting artifacts

\section{Purpose}

The purposes of this work are two fold: (a) to theoretically analyze and experimentally evaluate the impact of removing the startup shot in a conventional cardiac viability sequence, and (b) evaluate potential mechanisms for minimizing the artifacts stemming from the removal of start-up shots.

\section{Hypothesis}

We hypothesize that by reducing the flip-angle of the IR pulse during the first shot one can minimize the signal amplitude modulation between the shots.

\section{Theory and methods}

The magnetization preparation flip angle for the first shot was set to yield the steady state longitudinal magnetization for the tissue of interest. The variable flip angle was calculated as follows: With the user entered inversion time $(\mathrm{TI})$ value, and the time between IR

${ }^{1}$ Rice University, Houston, TX, USA

Full list of author information is available at the end of the article pulses, the apparent $\mathrm{T} 1$ of the tissue to be nulled is calculated for the given heart rate. Based on this T1, an inversion flip angle which would yield nulling at the desired Td for the first shot [Fig 1]. Each simulation was performed for three different tissue types that had apparent $\mathrm{T} 1$ values of $555 \mathrm{~ms}$ (tissue of interest), 1215 $\mathrm{ms}$ (longer T1) and $300 \mathrm{~ms}$ (shorter T1). Other simulation parameters were: TR/TE $/ \alpha=7 \mathrm{~ms} / 3 \mathrm{~ms} / 15^{\circ}$; TFE factor $=22$; startup echoes $=4$. The simulation was carried out for 7 RR intervals, each $1000 \mathrm{~ms}$ long, leading to 154 phase encoding steps. Phantoms with the desired $\mathrm{T} 1$ values (as simulated) were created using water and Magnevist $^{\circ}$ (Bayer Healthcare Pharmaceuticals, USA). Scanning was performed in a $1.5 \mathrm{~T}$ Achieva scanner (Philips Healthcare)

\section{Results}

The theoretical point-spread function of IR-TFE sequence with/without the start up shots is shown in Figure 2. Experimental findings confirm theoretical predictions. Figure 3 shows the efficacy of the variable flip angle preparation method, which yields significantly less artifacts than the conventional method.

\section{Conclusions}

Our theoretical and experimental models suggest that, by modulating the flip angle of the magnetization preparation pulse, it is possible to significantly reduce artifacts arising from accepting data from dummy shots.

\footnotetext{
Author details

${ }^{1}$ Rice University, Houston, TX, USA. ${ }^{2}$ Philips Health Care, Houston, TX, USA. ${ }^{3}$ St. Luke's Episcopal Hospital, Houston, TX, USA.
} 
(A)
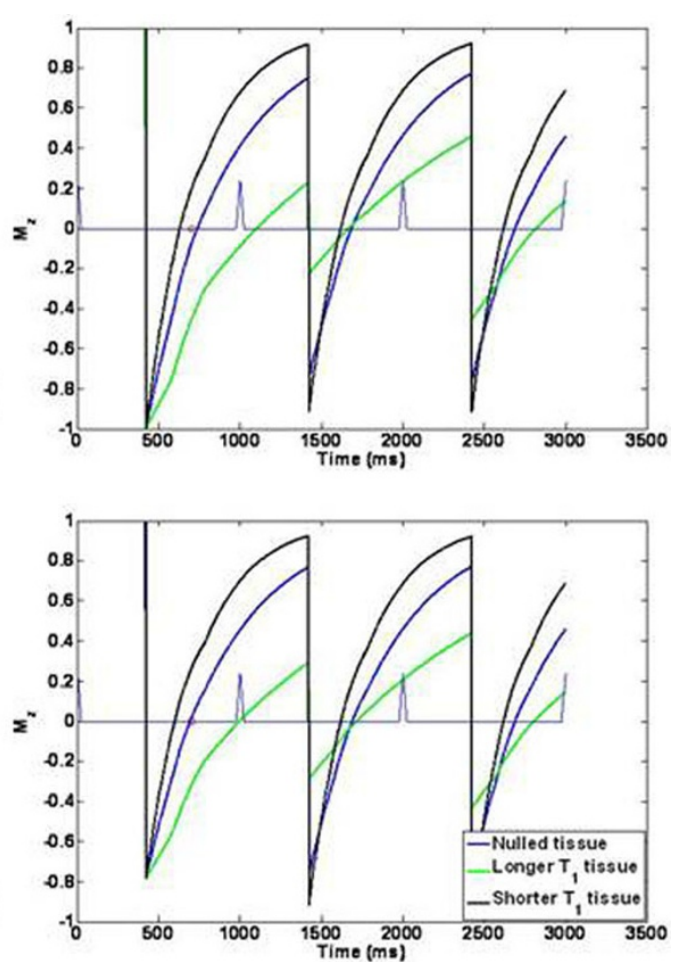

Figure 1
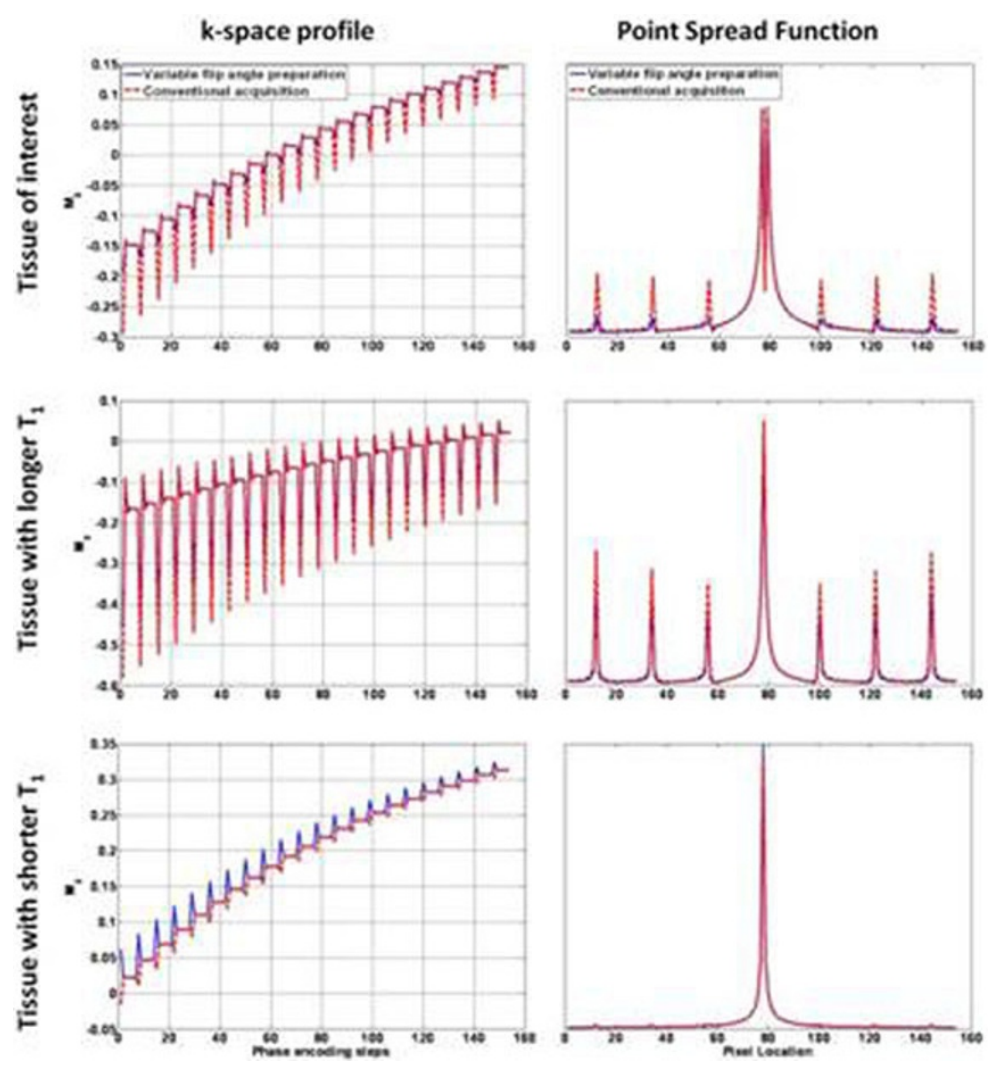

Figure 2 


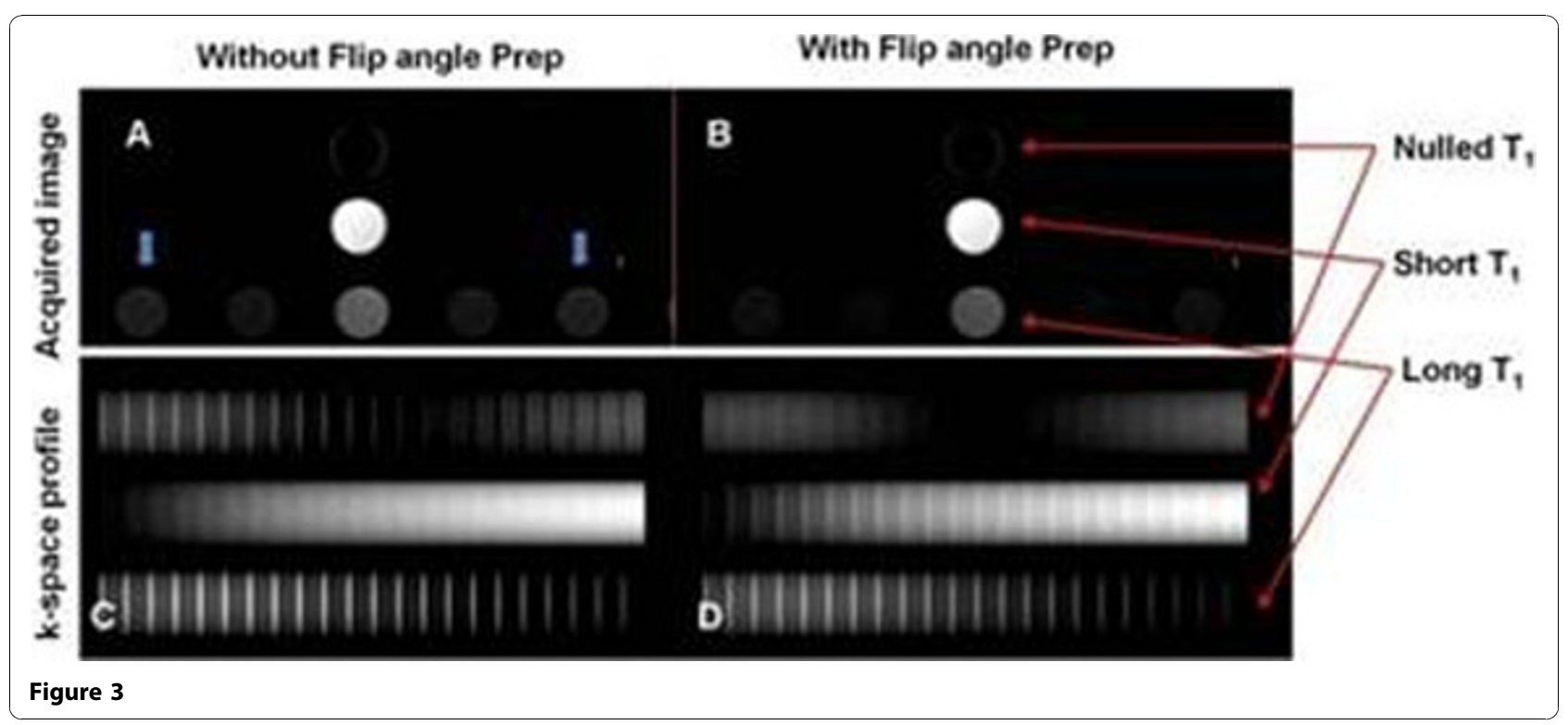

Published: 2 February 2011

doi:10.1186/1532-429X-13-S1-P28

Cite this article as: Krishnamurthy et al: Faster Inversion Recovery

Prepared T1 weighted segmented turbo field echo sequence (IR-TFE):

Evaluating options for eliminating the start-up shot. Journal of

Cardiovascular Magnetic Resonance 2011 13(Suppl 1):P28.

Submit your next manuscript to BioMed Central and take full advantage of:

- Convenient online submission

- Thorough peer review

- No space constraints or color figure charges

- Immediate publication on acceptance

- Inclusion in PubMed, CAS, Scopus and Google Scholar

- Research which is freely available for redistribution 